\title{
KELIMPAHAN DAN KEANEKARAGAMAN SPESIES LABA-LABA PREDATOR HAMA PADI RATUN DI SAWAH PASANG SURUT
}

\author{
Siti Herlinda ${ }^{1,3}$, Hendri Candro Nauli Manalu², Rinda Fajrin Aldina ${ }^{2}$, Suwandi ${ }^{1,3}$, \\ Andi Wijaya ${ }^{3}$, Khodijah ${ }^{4}$, \& Dewi Meidalima ${ }^{5}$ \\ ${ }^{1}$ Jurusan Hama dan Penyakit Tumbuhan, Fakultas Pertanian, Universitas Sriwijaya, Indralaya \\ ${ }^{2}$ Program Studi Agroekoteknologi, Fakultas Pertanian, Universitas Sriwijaya, Indralaya \\ ${ }^{3}$ Pusat Unggulan Riset Pengembangan Lahan Suboptimal (PUR-PLSO), Universitas Sriwijaya, Palembang \\ ${ }^{4}$ Jurusan Hama dan Penyakit Tumbuhan, Fakultas Pertanian, Universitas Palembang, Palembang \\ ${ }^{5}$ Program Studi Agroteknologi, Sekolah Tinggi Ilmu Pertanian Sriwigama, Palembang \\ E-mail: sitiherlinda@unsri.ac.id, sitiherlinda@drn.go.id
}

\begin{abstract}
Abundance and Species Diversity of Predatory Spiders for Insect Pests Inhabiting Ratoon Paddy in Tidal Lowland. Ratoon paddy productivity is lower than the main crop. Increasing productivity of the ratoon paddy is to protect the paddy from pests and diseases. This study aimed to analyze the abundance and species diversity of predatory spiders of rice pests on ratoon paddy in tidal lowland. Ratoon paddy field observed was from the main crop that has been harvested and cut $20 \mathrm{~cm}$ height. Paddy area observed was 2 ha field planted using Ciherang and Inpara varieties. Spiders inhabiting canopy were sampled using insect nets but soil dwelling spiders were trapped using pitfall traps. The result showed that spider species inhabiting canopy of ratoon paddy were Pardosa pseudoannulata, Lycosa chaperi, Araneus inustus, Cylosa insulana, Atypena adelinae, Erigone bifurca, Erigonidium graminicola, Oxyopes javanus, Argyrodes miniaceus, and Marpisa magister. Spider species found soil dwelling were 11 species, namely Pardosa pseudoannulata, Pardosa sumatrana, Pardosa mackenziei, Pardosa oakleyi, Hogna rizali, Araneus inustus, Cylosa insulana, T. vermiformis, Runcinia albostriata, Coleosoma octomaculatum, and Marpisa magister. Abundance, species number, species diversity for soil dwelling spiders were higher than those for canopy inhabiting spiders. However, the abundance, species number, species diversity for the soil dwelling spiders tended to be higher on the ratoon paddy 3,4 , and 5 week old than those on 1,2, and 6 week old. From the result, we concluded that abundance, species number, species diversity of spiders found in the ratoon paddy were higher or tended similar to those on the main crop.
\end{abstract}

Key words: abundance, biodiversity, ratoon, spiders

\section{ABSTRAK}

Kelimpahan dan keanekaragaman spesies laba-laba predator hama padi ratun di sawah pasang surut. Padi ratun produktivitasnya lebih rendah daripada padi utama, untuk itu upaya peningkatan produktivitas terus dilakukan, antara lain adalah melindungi padi ratun dari serangan hama dan penyakit. Penelitian ini bertujuan untuk menganalisis kelimpahan dan keanekaragaman spesies laba-laba predator hama padi ratun di sawah pasang surut. Lahan yang diamati, yaitu lahan padi yang sudah panen atau dipotong singgang dengan ketinggian kurang lebih $20 \mathrm{~cm}$. Luas sawah yang diamati, yaitu 2 ha yang memiliki varietas yang berbeda yaitu varietas Ciherang dan Inpara. Laba-laba penghuni tajuk diamati menggunakan jaring serangga, sedangkan penghuni permukaan tanah menggunakan perangkap lubang. Dari hasil penelitian ini ditemukan 10 spesies laba-laba yang menghuni tajuk padi singgang, yaitu Pardosa pseudoannulata, Lycosa chaperi, Araneus inustus, Cylosa insulana, Atypena adelinae, Erigone bifurca, Erigonidium graminicola, Oxyopes javanus, Argyrodes miniaceus, dan Marpisa magister. Spesies laba-laba predator yang ditemukan di permukaan tanah ada 11 spesies, yaitu Pardosa pseudoannulata, Pardosa sumatrana, Pardosa mackenziei, Pardosa oakleyi, Hogna rizali, Araneus inustus, Cylosa insulana, T. vermiformis, Runcinia albostriata, Coleosoma octomaculatum, dan Marpisa magister. Kelimpahan, jumlah spesies, maupun keanekaragaman spesies laba-laba di permukaan tanah lebih tinggi dibandingkan laba-laba penghuni tajuk. Akan tetapi kelimpahan, jumlah spesies, dan keanekaragaman spesies laba-laba penghuni permukaan tanah dan tajuk memiliki kecenderungan yang sama, yaitu lebih tinggi pada saat umur singgang 3, 4, dan 5 minggu dibanding umur singgang 1, 2, dan 6 minggu. Dari hasil penelitian disimpulkan bahwa kelimpahan dan keanekaragaman spesies laba-laba predator hama padi ratun tinggi dan beranekaragam.

Kata kunci: keanekaragaman, kelimpahan, padi singgang, spesies laba-laba 


\section{PENDAHULUAN}

Padi ratun (ratoon) yang dalam Bahasa Jawa disebut singgang atau turiang dalam Bahasa Sunda adalah tunggul tanaman padi yang tumbuh kembali setelah dipanen (Nair \& Rosamma, 2002). Tanaman padi yang dapat dimanfaatkan untuk dibudidayakan dengan sistem ratun ini biasanya varietas tertentu yang mampu menghasilkan tunas sekunder. Selain varietas, keberhasilan sistem ratun ini ditentukan juga oleh vigor tanaman utamanya. Vigor ini ditentukan oleh besarnya energi atau cadangan hasil proses fotosintesis yang dicirikan oleh batang utama yang masih hijau (Marschner, 1995). Asimilat tersebut akan digunakan untuk pertumbuhan tunas ratun (Wu et al., 1998). Sistem budidaya padi ratun ini umumnya telah berhasil dilakukan di berbagai daerah, antara lain di sentra sawah pasang surut di Sumatera Selatan.

Padi ratun produktivitasnya lebih rendah daripada padi utama, untuk itu upaya peningkatan produktivitas terus dilakukan, termasuk diantaranya adalah melindungi padi ratun dari serangan hama dan penyakit. Serangga hama yang ditemukan menyerang tanaman padi, antara lain wereng coklat, hama putih palsu, penggerek batang, dan penggulung daun (Khodijah et al., 2012). Hasil pengamatan langsung (data belum dipublikasikan), wereng coklat sangat dominan ditemukan di sentra padi ratun di daerah pasang surut di Sumatera Selatan. Wereng coklat hanya efektif dikendalikan oleh musuh alaminya, antara lain laba-laba. Untuk itu, perlu dikaji apakah kelimpahan dan keanekaragaman spesies labalaba cukup tinggi di sentra padi ratun di Sumatera Selatan. Penelitian ini bertujuan untuk menganalisis kelimpahan dan keanekaragaman spesies laba-laba predator hama padi ratun di sawah pasang surut.

\section{METODE PENELITIAN}

Tempat dan Waktu. Penelitian ini dilaksanakan di sentra lahan pasang surut Sumatera Selatan, yaitu di Desa Mulia Sari Kabupaten Banyuasin, yang dimulai sejak Februari hingga Agustus 2013. Pertanaman padi yang digunakan untuk penelitian ini terdapat di sentra pasang surut Sumatera Selatan dengan cara tebar benih langsung. Lahan yang diamati, yaitu lahan padi yang sudah dipanen atau dipotong singgang dengan ketinggian kurang lebih $20 \mathrm{~cm}$. Luas sawah yang diamati adalah 2 ha yang memiliki varietas yang berbeda, yaitu varietas Ciherang dan Inpara. Setiap 1 ha dibagi menjadi 4 subpetak, sedangkan setiap 1 subpetak diambil 5 rumpun sampel yang diamati kelimpahan laba-laba predator.
Pengamatan Laba-laba Predator pada Tajuk. Pengamatan laba-laba predator pada tajuk padi dengan menggunakan jaring serangga yang dilakukan pada pagi hari setiap 7 hari dengan tujuan laba-laba belum aktif sehingga mudah dalam pengambilannya. Pengambilan laba-laba predator dengan menggunakan jaring dilakukan 20 kali ayunan per ha. Panjang tangkai jaring serangga tersebut $100 \mathrm{~cm}$, mulut jaring terbuka dengan diameter $30 \mathrm{~cm}$ dan panjang kantong kain kasa $60 \mathrm{~cm}$. Dari setiap ayunan jaring, laba-laba yang tertangkap dimasukkan dalam kantong plastik yang berbeda yang di dalamnya telah berisi larutan $100 \mathrm{ml}$ formalin 2\%. Pengambilan laba-laba predator ini dilakukan untuk mengetahui kelimpahan atau jumlah individu, dan keanekaragaman spesies laba-laba predator. Laba-laba yang tertangkap selanjutnya dibawa ke laboratorium, lalu disortasi dan dibersihkan dari formalin dengan menggunakan air, lalu dimasukkan ke dalam botol vial yang berisi alkohol $70 \%$. Akhirnya, spesimen laba-laba tersebut diidentifikasi di Laboratorium Entomologi Jurusan Hama dan Penyakit Tumbuhan Fakultas Pertanian Universitas Sriwijaya.

Pengamatan Laba-laba Predator pada Permukaan Tanah. Untuk laba-laba predator yang aktif pada permukaan tanah diambil menggunakan perangkap lubang (pitfall trap) yang dipasang sebanyak 12 perangkap per ha. Perangkap lubang dipasang setiap 7 hari dan dibiarkan terpasang selama $2 \times 24$ jam. Pengambilan contoh laba-laba predator ini dimulai pada fase vegetatif hingga generatif. Perangkap lubang berisi formalin $4 \%$ sebanyak sepertiga gelas plastik, kemudian di atasnya diberi tutup pelindung dengan tiang penyangga menggunakan lidi atau kayu kecil. Tujuan diberi tutup agar air hujan atau sampah lainnya tidak ikut masuk ke dalam perangkap lubang. Ukuran gelas plastik untuk perangkap lubang tersebut adalah bervolume $240 \mathrm{ml}$ dengan diameter $75 \mathrm{~mm}$ dan tinggi atau kedalaman gelas $100 \mathrm{~mm}$. Laba-laba predator yang terperangkap dari perangkap lubang disortasi, disaring dengan saringan ukuran pori $1 \mathrm{~mm}$, lalu dibilas dengan air mengalir dan dimasukkan ke dalam botol vial berisi alkohol $70 \%$. Selanjutnya spesimen tersebut diidentifikasi menggunakan mikroskop binokuler dan dihitung jumlah individunya di laboratorium untuk mengetahui kelimpahannya. Identifikasi laba-laba menggunakan buku Kalshoven (1981) dan Barrion \& Litsinger (1994).

Analisis Data. Data komposisi spesies dan jumlah individu laba-laba digunakan untuk menganalisis kelimpahan dan keanekaragaman spesies. Ukuran keanekaragaman yang digunakan ialah indeks keanekaragaman spesies Shannon Wienner, Indeks 
dominasi spesies Berger-Parker dan Indeks kemerataan spesies dari Pielou (Fachrul, 2007).

\section{HASIL DAN PEMBAHASAN}

Dari hasil penelitian ini ditemukan 10 spesies labalaba yang menghuni tajuk padi singgang, yaitu Pardosa pseudoannulata, Lycosa chaperi, Araneus inustus, Cylosa insulana, Atypena adelinae, Erigone bifurca, Erigonidium graminicola, Oxyopes javanus, Argyrodes miniaceus, dan Marpisa magister (Tabel 1). Spesies yang ditemukan pada tajuk padi ini merupakan laba-laba pemburu (hunting spider) dan pembuat jaring (web spider). Famili yang merupakan laba-laba pembuat jaring adalah Araneidae, sedangkan sisanya adalah laba-laba pemburu (Lycosidae, Linyphiidae, Oxyopidae, Theridiidae, dan Salticidae) (Tabel 1). Saat pengambilan contoh laba-laba menggunakan jaring serangga, tidak ditemukan famili Tetragnathidae yang merupakan laba-laba pembuat jaring. Sebaliknya, Tetragnathidae, seperti Tetragnatha vermiformis ditemukan pada permukaan tanah (Tabel 2). Hal ini dapat disebabkan oleh perilaku spesies tersebut walaupun pembuat jaring tetapi mampu bergerak dan berjalan di permukaan tanah dan air. Linyphiidae merupakan laba-laba yang memiliki mobilitas tinggi tetapi menangkap mangsa dengan menggunakan jaringnya (Schmidt \& Tscharntke, 2005). Laba-laba pemburu dapat ditemukan di tajuk karena mobilitas mereka lebih tinggi mampu berpindah-pindah baik dari permukaan tanah menuju tajuk atau sebaliknya, sedangkan laba-laba pembuat jaring cenderung sedikit ditemukan di permukaan tanah.

Jumlah individu atau kelimpahan laba-laba yang ditemukan pada tajuk padi singgang baik pada varietas Ciherang maupun Inpara secara keseluruhan menunjukkan kecenderungan yang mirip. Kelimpahan laba-laba yang didapatkan menggunakan jaring serangga 66,07 ekor per 20 jaring pada varietas Ciherang dan 71,77 ekor per 20 jaring pada varietas Inpara. Pada kedua habitat tersebut, spesies laba-laba dari Famili Salticidae, Marpisa magister mendominasi. Urutan kedua didominasi oleh Famili Lycosidae. Salticidae dan Lycosidae merupakan laba-laba pemburu yang memiliki mobilitas lebih tinggi dibandingkan laba-laba pembuat jaring. Dengan demikian, kedua famili tersebut mudah ditemukan baik pada tajuk maupun permukaan tanah.

Spesies laba-laba predator yang ditemukan di permukaan tanah pada pertanaman padi singgang ada 11 spesies, yaitu Pardosa pseudoannulata, $P$. sumatrana, P. mackenziei, P. oakleyi, Hogna rizali, Araneus inustus, Cylosa insulana, T. vermiformis, Runcinia albostriata, Coleosoma octomaculatum, dan Marpisa magister (Tabel 2). Laba-laba Famili Lycosidae mendominasi ditemukan di permukaan tanah karena laba-laba tersebut memiliki kemampuan mobilitas

Tabel 1. Spesies laba-laba predator hama padi di tajuk tanaman padi singgang selama satu musim tanam

\begin{tabular}{|c|c|c|}
\hline \multirow{2}{*}{ Famili/Spesies } & \multicolumn{2}{|c|}{ Rata-rata kelimpahan laba-laba (ekor/20 jaring) } \\
\hline & Varietas Ciherang & Varietas Inpara \\
\hline \multicolumn{3}{|l|}{ Lycosidae } \\
\hline Pardosa pseudoannulata & 5,50 & 6,67 \\
\hline Lycosa chaperi & 8,80 & 8,60 \\
\hline \multicolumn{3}{|l|}{ Araneidae } \\
\hline Araneus inustus & 2,00 & 7,00 \\
\hline Cylosa insulana & 10,25 & 1,00 \\
\hline \multicolumn{3}{|l|}{ Linyphiidae } \\
\hline Atypena adelinae & 2,00 & \\
\hline Erigone bifurca & 4,50 & 5,17 \\
\hline Erigonidiumgraminicola & 3,25 & 6,00 \\
\hline \multicolumn{3}{|l|}{ Oxyopidae } \\
\hline Oxyopes javanus & 7,60 & 11,33 \\
\hline \multicolumn{3}{|l|}{ Theridiidae } \\
\hline Argyrodes miniaceus & 7,50 & 8,33 \\
\hline \multicolumn{3}{|l|}{ Salticidae } \\
\hline Marpisa magister & 13,17 & 17,67 \\
\hline Total & 66,07 & 71,77 \\
\hline
\end{tabular}


Tabel 2. Spesies laba-laba predator hama padi pada permukaan tanah di ekosistem padi singgang selama satu musim tanam

\begin{tabular}{lcc}
\hline \multirow{2}{*}{ Famili/Spesies } & Rata-rata kelimpahan laba-laba (ekor/12 perangkap) \\
\cline { 2 - 3 } & Varietas Ciherang & Varietas Inpara \\
\hline Lycosidae & 6,00 & 4,50 \\
$\quad$ Pardosa pseudoannulata & 0,00 & 0,17 \\
$\quad$ Pardosa sumatrana & 0,00 & 0,33 \\
$\quad$ Pardosa mackenziei & 3,33 & 3,83 \\
$\quad$ Pardosa oakleyi & 0,17 & 0,00 \\
$\quad$ Hogna rizali & 0,00 & 0,00 \\
Araneidae & 0,50 & 1,17 \\
$\quad$ Araneus inustus & 0,50 & 0,00 \\
$\quad$ Cylosa insulana & & \\
Tetragnathidae & 0,50 & 0,17 \\
$\quad$ Tetragnatha vermiformis & & 0,00 \\
Thomisidae & 0,17 & 0,00 \\
$\quad$ Runcinia albostriata & & 0,00 \\
Theridiidae & 0,17 & 0,00 \\
$\quad$ Coleosoma octomaculatum & 0,00 & 10,17 \\
Salticidae & 0,33 & \\
$\quad$ Marpisa magister & 11,67 & \\
\hline$\quad$ Total & & \\
\hline
\end{tabular}

dan aktivitas tinggi di permukaan tanah (Denno et al., 2004). Selain Lycosidae laba-laba pemburu lainnya adalah Thomisidae, Theridiidae, dan Salticidae. Labalaba pembuat jaring masih ditemukan di permukaan tanah adalah Araneidae dan Tetragnathidae. Pada penelitian ini, laba-laba pembuat jaring tersebut ditemukan pada fase pradewasa. Fase pradewasa tersebut dapat diterbangkan dan jatuh ke permukaan tanah karena mengikuti arah angin sehingga dapat tertangkap oleh perangkap lubang yang dipasang pada penelitian ini.

Karakteristik komunitas laba-laba di permukaan tanah (Tabel 3) menunjukkan perbedaan dengan komunitas laba-laba yang ditemukan di tajuk (Tabel 4). Fenomena karakteristik komunitas laba-laba pada pertanaman padi singgang ini mirip dengan komunitas laba-laba pada padi utama hasil penelitian Herlinda et al. (2008). Jumlah individu atau kelimpahan, jumlah spesies, maupun keanekaragaman spesies laba-laba di permukaan tanah lebih tinggi dibandingkan laba-laba penghuni tajuk. Akan tetapi kecenderungan untuk kelimpahan, jumlah spesies, dan keanekaragaman spesies laba-laba penghuni permukaan tanah dan tajuk memiliki kemiripan, yaitu pada umur singgang 3, 4, dan 5 minggu cenderung lebih tinggi dibanding umur singgang
1, 2, dan 6 minggu. Umur singgang 3, 4, dan 5 minggu merupakan fase generatif padi singgang, yaitu buah padi sudah muncul saat umur singgang 3 minggu dan saat singgang 5 minggu bulir padi mulai mengalami matang susu. Pada fase generatif seperti ini menurut Herlinda et al. (2008) merupakan fase berlimpah untuk serangga entomofaga (predator dan parasitoid). Berlimpahnya artropoda predator baik serangga maupun laba-laba disebabkan semakin berlimpahnya serangga fitofag dan serangga penyerbuk di tanaman padi (Schmitz, 2003; Herlinda et al., 2004). Serangga fitofag dan penyerbuk, serta serangga pengurai merupakan serangga yang menjadi mangsa atropoda predator (Ishijima et al., 2006). Artropoda predator, seperti laba-laba memiliki mangsa utama dari kelompok wereng, terutama wereng coklat (Preap et al., 2001). Pada saat kelimpahan mangsa lebih tinggi, maka cenderung kelimpahan labalaba lebih tinggi juga dan kelimpahan laba-laba pradewasa yang melakukan penyebaran juga lebih tinggi (Iida \& Fujisaki, 2007). Hal ini disebabkan laba-laba memiliki tanggap fungsional yang baik yang merupakan ciri-ciri predator yang efektif (Preap et al., 2001; Denno et al., 2004;Wilby et al., 2005). 
Tabel 3. Karakteristik komunitas laba-laba predator hama padi di tajuk tanaman padi singgang

\begin{tabular}{|c|c|c|c|}
\hline $\begin{array}{c}\text { Umur singgang } \\
\text { (minggu) }\end{array}$ & Karekteristik komunitas & Varietas Ciherang & Varietas Inpara \\
\hline \multirow{5}{*}{1} & Jumlah individu (N) (ekor/20 jaring) & 59,00 & 61,00 \\
\hline & Jumlah spesies & 6,00 & 7,00 \\
\hline & Indeks keanekaragaman $\left(\mathrm{H}^{\prime}\right)$ & 1,56 & 1,62 \\
\hline & Indeks dominasi $(\mathrm{d})$ & 0,44 & 0,28 \\
\hline & Indeks kemerataan $(\mathrm{E})$ & 0,26 & 0,83 \\
\hline \multirow{5}{*}{2} & Jumlah individu (N) (ekor/20 jaring) & 38,00 & 53,00 \\
\hline & Jumlah spesies & 6,00 & 7,00 \\
\hline & Indeks keanekaragaman $\left(\mathrm{H}^{\prime}\right)$ & 1.62 & 1,71 \\
\hline & Indeks dominasi $(\mathrm{d})$ & 0.34 & 0,36 \\
\hline & Indeks kemerataan $(\mathrm{E})$ & 0.91 & 0,88 \\
\hline \multirow{5}{*}{3} & Jumlah individu (N) (ekor/20 jaring) & 56,00 & 77,00 \\
\hline & Jumlah spesies & 7,00 & 7,00 \\
\hline & Indeks keanekaragaman $\left(\mathrm{H}^{\prime}\right)$ & 1,85 & 1,54 \\
\hline & Indeks dominasi (d) & 0,29 & 0,48 \\
\hline & Indeks kemerataan $(\mathrm{E})$ & 0,95 & 0,79 \\
\hline \multirow{5}{*}{4} & Jumlah individu (N) (ekor/20 jaring) & 75,00 & 72,00 \\
\hline & Jumlah spesies & 8,00 & 6,00 \\
\hline & Indeks keanekaragaman $\left(\mathrm{H}^{\prime}\right)$ & 1,75 & 1,59 \\
\hline & Indeks dominasi $(\mathrm{d})$ & 0,31 & 0,31 \\
\hline & Indeks kemerataan $(\mathrm{E})$ & 0,84 & 0,89 \\
\hline \multirow{5}{*}{5} & Jumlah individu (N) (ekor/20 jaring) & 48,00 & 83,00 \\
\hline & Jumlah spesies & 6,00 & 7,00 \\
\hline & Indeks keanekaragaman $\left(\mathrm{H}^{\prime}\right)$ & 1,68 & 1,86 \\
\hline & Indeks dominasi $(\mathrm{d})$ & 0,31 & 0,22 \\
\hline & Indeks kemerataan $(\mathrm{E})$ & 0,94 & 0,96 \\
\hline \multirow{5}{*}{6} & Jumlah individu (N) (ekor/20 jaring) & 27,00 & 15,00 \\
\hline & Jumlah spesies & 5,00 & 6,00 \\
\hline & Indeks keanekaragaman $\left(\mathrm{H}^{\prime}\right)$ & 1,52 & 1,59 \\
\hline & Indeks dominasi $(\mathrm{d})$ & 0.33 & 0,40 \\
\hline & Indeks kemerataan $(\mathrm{E})$ & 0,94 & 0,89 \\
\hline
\end{tabular}

Jumlah individu atau kelimpahan, jumlah spesies, maupun keanekaragaman spesies laba-laba di permukaan tanah lebih tinggi dibandingkan laba-laba penghuni tajuk. Hal ini disebabkan juga lama waktu pengambilan contoh untuk laba-laba penghuni permukaan tanah $2 \times 24$ jam (siang dan malam hari), sedangkan pengambilan contoh laba-laba penghuni tajuk dilakukan hanya pada siang hari. Menurut Karindah (2011), aktifitas pergerakan predator dalam mencari mangsa dapat terjadi siang maupun malam. Dengan demikian, bila pengambilan contoh dilakukan baik siang maupun malam akan mendapat kelimpahan yang lebih tinggi. Selain itu, menurut Sudarjat et al. (2009), dinamika kelimpahan predator ditentukan juga dengan dinamika mangsanya. Predator yang efektif cenderung mengumpul pada habitat yang populasi mangsanya tinggi (Sudarjat et al., 2009; Karindah, 2011) atau meningkat kemampuan memangsanya bila populasi mangsa meningkat (Nelly et al., 2012). 
Tabel 4. Karakteristik komunitas laba-laba predator hama padi pada permukaan tanah di ekosistem padi singgang

\begin{tabular}{|c|c|c|c|}
\hline $\begin{array}{l}\text { Umur singgang } \\
\text { (minggu) }\end{array}$ & Karekteristik komunitas & Varietas Ciherang & Varietas Inpara \\
\hline \multirow{5}{*}{1} & Jumlah individu (N) (ekor/12 perangkap) & 14,00 & 10,00 \\
\hline & Jumlah spesies & 5,00 & 3,00 \\
\hline & Indeks keanekaragaman $\left(\mathrm{H}^{\prime}\right)$ & 1,43 & 0,94 \\
\hline & Indeks dominasi (d) & 0,36 & 0,50 \\
\hline & Indeks kemerataan $(\mathrm{E})$ & 0,89 & 0,86 \\
\hline \multirow{5}{*}{2} & Jumlah individu (N) (ekor/12 perangkap) & 11,00 & 12,00 \\
\hline & Jumlah spesies & 4,00 & 3,00 \\
\hline & Indeks keanekaragaman $\left(\mathrm{H}^{\prime}\right)$ & 1,24 & 0,92 \\
\hline & Indeks dominasi (d) & 0,45 & 0,50 \\
\hline & Indeks kemerataan $(\mathrm{E})$ & 0,89 & 0,84 \\
\hline \multirow{5}{*}{3} & Jumlah individu (N) (ekor/12 perangkap) & 11,00 & 13,00 \\
\hline & Jumlah spesies & 2,00 & 3,00 \\
\hline & Indeks keanekaragaman $\left(\mathrm{H}^{\prime}\right)$ & 0,69 & 0,91 \\
\hline & Indeks dominasi (d) & 0,55 & 0,46 \\
\hline & Indeks kemerataan $(\mathrm{E})$ & 0,99 & 0,83 \\
\hline \multirow{5}{*}{4} & Jumlah individu (N) (ekor/12 perangkap) & 13,00 & 12,00 \\
\hline & Jumlah spesies & 5,00 & 4,00 \\
\hline & Indeks keanekaragaman $\left(\mathrm{H}^{\prime}\right)$ & 1,38 & 1,20 \\
\hline & Indeks dominasi (d) & 0,46 & 0,50 \\
\hline & Indeks kemerataan $(\mathrm{E})$ & 0,86 & 0,86 \\
\hline \multirow{5}{*}{5} & Jumlah individu (N) (ekor/12 perangkap) & 15,00 & 7,00 \\
\hline & Jumlah spesies & 3,00 & 4,00 \\
\hline & Indeks keanekaragaman $\left(\mathrm{H}^{\prime}\right)$ & 0,73 & 1,35 \\
\hline & Indeks dominasi (d) & 0,73 & 0,29 \\
\hline & Indeks kemerataan $(\mathrm{E})$ & 0,66 & 0,98 \\
\hline \multirow{5}{*}{6} & Jumlah individu (N) (ekor/12 perangkap) & 6,00 & 7,00 \\
\hline & Jumlah spesies & 3,00 & 3,00 \\
\hline & Indeks keanekaragaman $\left(\mathrm{H}^{\prime}\right)$ & 0,87 & 0,96 \\
\hline & Indeks dominasi (d) & 0,67 & 0,57 \\
\hline & Indeks kemerataan $(\mathrm{E})$ & 0,79 & 0,87 \\
\hline
\end{tabular}

\section{SIMPULAN}

Dari penelitian ini ditemukan 10 spesies laba-laba yang menghuni tajuk padi singgang, yaitu Pardosa pseudoannulata, Lycosa chaperi, Araneus inustus, Cylosa insulana, Atypena adelinae, Erigone bifurca, Erigonidium graminicola, Oxyopes javanus, Argyrodes miniaceus, dan Marpisa magister. Spesies laba-laba predator yang ditemukan di permukaan tanah ada 11 spesies, yaitu $P$. seudoannulata, $P$. sumatrana, P. mackenziei, P. oakleyi, Hogna rizali, Araneus inustus, Cylosa insulana, T. vermiformis, Runcinia albostriata, Coleosoma octomaculatum, dan Marpisa magister. Kelimpahan, jumlah spesies, maupun keanekaragaman spesies laba-laba di permukaan tanah lebih tinggi dibandingkan laba-laba penghuni tajuk, namun kelimpahan, jumlah spesies, dan keanekaragaman spesies laba-laba penghuni permukaan tanah dan tajuk memiliki kecenderungan yang sama, yaitu lebih tinggi pada saat umur singgang 3 , 4, dan 5 minggu dibanding umur singgang 1, 2, dan 6 minggu. Kelimpahan dan keanekaragaman spesies laba-laba predator hama padi ratun tergolong tinggi dan beranekaragam. 


\section{SANWACANA}

Penelitian ini bagian dari Penelitian Hibah Kompetensi yang dibiayai oleh Direktorat Jenderal Pendidikan Tinggi, Kementerian Pendidikan dan Kebudayaan, sesuai dengan Surat Perjanjian Penugasan dalam Rangka Pelaksanaan Program Penelitian Hibah Kompetensi Tahun Anggaran 2013, Nomor: 093.a/ UN9.3.1/PL/2013, Tanggal 13 Mei 2013 yang diketuai oleh Siti Herlinda.

\section{DAFTAR PUSTAKA}

Barrion AT \& Litsinger JA. 1994. Taxonomy of rice insect pest and their arthropod parasites and predators. In: Heinrichs EA (Eds.). Biology and Management of Rice Insects. International Rice Research Institute, Philippines. pp.13-362.

Denno RF, Mitter MS, Langellotto GA, Gratton C, \& Finke DL. 2004. Interactions between a hunting spider and a web-builder: consequences of intraguild predation and cannibalism for prey suppression. Ecol. Entomol. 29(5): 566-577.

Fachrul MF. 2007. Metode Sampling Bioekologi. Bumi Aksara, Jakarta.

Herlinda S, Rauf A, Sosromarsono S, Kartosuwondo U, Siswadi, \& Hidayat P. 2004. Artropoda musuh alami penghuni ekosistem persawahan di daerah Cianjur, Jawa Barat. J. Entomol. Indon. 1(1): 9-15.

Herlinda S, Waluyo, Estuningsih SP, \& Irsan C. 2008. Perbandingan keanekaragaman spesies dan kelimpahan arthropoda predator penghuni tanah di sawah lebak yang diaplikasi dan tanpa aplikasi insektisida. J. Entomol. Indones. 5(2):96-107.

Iida H \& Fujisaki K. 2007. Seasonal changes in resource allocation within an individual offspring of the wolf spider, Pardosa pseudoannulata (Araneae: Lycosidae). Physiol. Entomol. 32(1): 81-86.

Ishijima C, Taguchi A, Takagi M, Motobayashi T, Nakai M, \& Kunimi Y. 2006. Observational evidence that the diet of wolf spiders (Araneae: Lycosidae) in paddies temporarily depends on dipterous insects. Appl. Entomol. Zool. 41(2): 195-200.

Kalshoven LGE. 1981. The Pests of Crops in Indonesia. Ichtiar Baru-Van Hoeve. Jakarta.
Karindah S. 2011. Predation of five generalist predators on brownplanthopper (Nilaparvata lugens Stål). J. Entomol. Indon. 8(2): 55-62.

Khodijah, Herlinda S, Irsan C, Pujiastuti Y, \& Thalib R. 2012. Artropoda predator penghuni ekosistem persawahan lebak dan pasang surut Sumatera Selatan. J. Lahan Suboptimal 1(1): 57-63.

Marschner H. 1995. Mineral Nutrition of Higher Plants. 2nd Ed. Academic Press Harcourt Brace and Company, London.

Nair AS \& Rosamma CA. 2002. Character association in ratoon crop of rice (Oryza sativa L.). J. Trop Agric. 40(2): 1-3.

Nelly N, Trizelia, \& Syuhadah Q. 2012. Tanggap fungsional Menochilus sexmaculatus Fabricius (Coleoptera: Coccinellidae) terhadap Aphis gossypii (Glover) (Homoptera: Aphididae) pada umur tanaman cabai berbeda. J. Entomol. Indon. 9(1): 23-31.

Preap V, Zalucki MP, Jahn GC, \& Nesbitt HJ. 2001. Effectiveness of brown planthopper predators: population suppression by two species of spider, Pardosa Pseudoannulata (Araneae, Lycosidae) and Araneus inustus (Araneae, Araneidae). J. Asia-Pacific Entomol. 4(2): 187-193.

Schmidt MH \& Tscharntke T. 2005. Landscape context of sheetweb spider (Araneae: Linyphiidae) abundance in cereal fields. J. Biogeography 32(3): 467-473.

Schmitz OJ. 2003. Top predator control of plant biodiversity and productivity in an old-field ecosystem. Ecol. Lett. 6(2): 156-163.

Sudarjat, Utomo A, \& Dono D. 2009. Biologi dan kemampuan memangsa Paederus fuscipes Curtis (Coleoptera: Staphylinidae) terhadap Bemisia tabaci Gennadius (Homoptera: Aleyrodidae). J. Agrikultura 20(3): 204-209.

Wilby A, Villareal SC, Lan LP, Heong KL, \& Thomas MB. 2005. Functional benefits of predator species diversity depend on prey identity. Ecol. Entomol. 30(5): 497-501.

Wu G, Wilson LT, \& McClung AM. 1998. Contribution of rice tillers to dry matter accumulation and yield. Agron J. 90(3): 317-323. 